Evidencia de Rizobios en Nódulos de Leucaena leucocephala (Lam.), mediante técnicas físico-químicas de cultivo y Microscopía Electrónica de Barrido (SEM)

Soto, J, Amano, Y, Díaz, L. 


\title{
Evidencia de Rizobios en Nódulos de Leucaena leucocephala (Lam.), mediante técnicas físico-químicas de cultivo y Microscopía Electrónica de Barrido (SEM)
}

\author{
Evidence of rhizobium in Leucaena leucocephala nodules (Lam.), Using \\ physicochemical culture techniques and scanning electron microscopy (SEM)
}

\author{
Soto, J. ${ }^{1} ;$ Amano, Y. ${ }^{2}$ y Díaz, L. ${ }^{2}$ \\ (1) Centro de Investigaciones Agropecuarias, Universidad Estatal Península de Santa Elena. \\ (2) Instituto Nacional de Investigación en Salud Pública "Dr. Leopoldo Izquieta Pérez. \\ jsotovalenzuela@yahoo.com ${ }^{(1)}$
}

\begin{abstract}
Resumen
Leucaena leucocephala L., es una Fabaceae con potencial agroforestal multipropósito en Asia y África, mientras que en Mesoamérica, de donde es originaria, es tratada por lo general como maleza para corte de leña y carbón. Su estudio establece que son excelentes productoras de biomasa en épocas de sequía y como toda leguminosa entra en simbiosis con sus huéspedes rizobios para fijar nitrógeno en el suelo. Con el objetivo de identificar y caracterizar la presencia de bacterias endofitas al interior de los nódulos de L. leucocephala se emplearon técnicas de cultivo en medio Levadura, Manitol, Agar Rojo Congo (LMRC), pruebas de tinción Gram, catalasa, velocidad de crecimiento, morfología de las colonias, producción de ácido y crecimiento en cloruro de sodio de los aislados; complementadas con técnicas de microscopía electrónica de barrido (SEM). Se evidenció la presencia de bacterias en el interior de sus raíces noduladas y en cultivo in vitro, colectadas en los campus de prácticas de la Universidad Estatal Península de Santa Elena (provincia de Santa Elena, Ecuador). Todas las bacterias presentaron características fenotípicas y bioquímicas asignadas al grupo de los rizobios en su interacción con una leguminosa silvestre poco estudiada y aprovechada en la zona.
\end{abstract}

Palabras Claves: Rizobios, Leucaena leucocephala, Microscopía Electrónica de Barrido (SEM), Gram negativas.

\begin{abstract}
Leucaena leucocephala L., is a Fabaceae with multipurpose agroforestry potential in Asia and Africa, while in Mesoamerica, where it originates, it is usually treated as a weed for cutting firewood and charcoal. Their study establishes that they are excellent producers of biomass in times of drought and how all legumes enter into symbiosis with their rhizobial hosts to fix nitrogen in the soil. In order to identify and characterize the presence of endophytic bacteria within L. leucocephala nodules, yeast, Mannitol, Congo Red Agar (LMRC) culture techniques, Gram stain tests, catalase, growth rate were used. colony morphology, acid production and growth in sodium chloride of isolates; complemented with scanning electron microscopy (SEM) techniques. The presence of bacteria inside the nodular roots and in vitro culture was evidenced, collected in the practice campuses of the Península de Santa Elena State University (Santa Elena province, Ecuador). All the bacteria presented phenotypic and biochemical characteristics assigned to the group of rhizobia in their interaction with a wild legume little studied and exploited in the area.
\end{abstract}

Keywords: Rhizobia, Leucaena leucocephala, Scanning Electron Microscopy (SEM), Gram negative. 


\section{Introducción}

Las leguminosas como Leucaena leucocephala (Lam.), pueden favorecer la producción de biomasa de calidad, en temporadas de disminución de las precipitaciones, debido a que poseen un sistema radical pivotante y a la facultad de asociarse con bacterias fijadoras de nitrógeno como Rhizobium, Bradyrhizobium y Mesorhizobium (Xu, et al. 2012; Aguirre-Medina, et al. 2015 y Elzanaty, et al. 2015).

L. leucocephala es una especie ampliamente investigada desde sus propiedades antihelmínticas (Soares, et al. 2015), hasta su empleo multipropósito en los sistemas agroforestales a nivel mundial, más conocida en el Sureste de Asia y en África que en Mesoamérica, donde se originó, es capaz de nodular espontáneamente con los rizobios del lugar, lo que le permite buena adaptación aún en sitios con factores limitantes (nutrición y disponibilidad de agua), lo que le genera una ventaja a nivel ecológico (Schneider, et al. 2013; Peix, et al. 2015 y Rangel, et al. 2017).

En la formación de nódulos, los rizobios quedan separados del citoplasma por una membrana derivada de la planta hospedadora, llamada membrana peribacteroidal (MPB). Seguido de una división continua y sincronizada de los rizobios rodeados de MPBs. Al cesar la división las bacterias se transforman en unas formaciones ramificadas, hinchadas y deformes, llamadas bacteroides (Wang, et al 2001).

Chen y Rolfe (1988), empleando microscopía electrónica de barrido (Scanning Electron Microscopy, SEM) al interior de las raíces, revelaron la deformación de los pelos radiculares por la infección con un Rhizobium de crecimiento rápido (cepa NGR234), y a partir de esta infección evidencian formas bacteroidales al interior de los nódulos de la leguminosa $L$. leucocephala. Tu (1974) también encontró células de tamaño uniforme bacteroidales, al interior de los nódulos de soya (Glycine max) empleando TEM (Transmission Electron Microscopy) y complementado por SEM.

Trinick (1979), mediante SEM y TEM, menciona que el hilo de la infección propagada por Rhizobium a nuevas células, se transformó en una célula de nódulos. Las paredes de los hilos variaron mucho en grosor y a menudo las estructuras de hilo no tenían paredes rígidas y sólo están encerradas por una membrana plasmática.

En la provincia de Santa Elena, Ecuador, L. leucocephala se presenta como una especie alternativa resistente a las sequías para reforestar suelos afectados por la salinidad y cambio climático de la zona, potencializada con una selección de cepas capaces de fijar nitrógeno, promover el crecimiento y resistir ciertas enfermedades (CEDEGÉ, 1983; Soto, et al. 2012 y Soto, et al. 2016).

El objetivo de este trabajo fue caracterizar y evidenciar la presencia de bacterias endófitas al interior de los nódulos de L. leucocephala, de gran importancia para establecer su asociación simbiótica con sus bacterias, en beneficio de su establecimiento adaptativo óptimo en las condiciones de la zona.

\section{Materiales y Métodos}

\subsection{Aislamiento de los nódulos}

Se colectaron muestras de hojas, inflorescencia y raíces con presencia de nódulos de Leucaena leucocephala (Lam.) localizadas en los campus de prácticas agrícolas de la Universidad Estatal Península de Santa Elena (Ecuador), ubicadas en las localidades de Río Verde (-2.31096, -80.7056) y La Libertad (2.24887, -80.858) (Figura 1); luego fueron guardadas y rotuladas en bolsas estériles. En el laboratorio se lavaron cuidadosamente con agua corriente y destilada estéril (Hernández, 2012).

Las muestras vegetales se identificaron en el Herbario de la Universidad de Guayaquil (Ecuador). Los aislamientos y pruebas de caracterización bioquímica de las bacterias se realizaron en el laboratorio del Centro de Investigaciones Agropecuarias (CIAP-UPSE), Facultad de Ciencias Agropecuarias de la Universidad Estatal Península de Santa Elena, mediante métodos descritos por el CIAT, 1987; Ferrera et al. 1993 y Zúñiga, 2012.

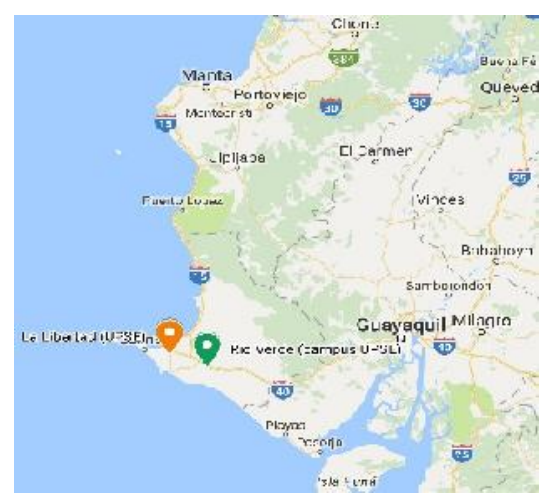

Figura 1. Localización de los sitios de muestreo en la península de Santa Elena, Ecuador.

Los nódulos se desinfectaron en alcohol al $95 \%$ y solución de cloro al $5 \%$ por 5 min respectivamente; enjuagados con agua destilada, macerados y sembrados por triplicado en cajas Petri con medio de cultivo 
Extracto de Levadura-Manitol-Agar Rojo-Congo LMARC). Luego fueron rotulados e incubados por 72 horas a $27{ }^{\circ} \mathrm{C}$.

\subsection{Caracterización fenotípica:}

a) Descripción microscópica de luz y macroscópica de los aislados

Se emplearon microscopios de luz, objetivo 100x inmersión en aceite, para la tinción Gram de las cepas. La descripción macroscópica también incluyó la producción de goma y velocidad de crecimiento de los aislados en las cajas de Petri con medio LMARC (Ferrera y Alarcón, 2001).

\section{b) Descripción microscópica electrónica de} Barrido (SEM)

La ultramicroscopía se realizó en el Instituto de Investigaciones en Salud Pública (INSPI Guayaquil, Ecuador) con un microscopio electrónico de barrido (MEB) marca JEOL JSM 5310, en cortes del interior de los nódulos y de cultivos aislados en cajas Petri, como servicio profesional.

\subsection{Caracterización bioquímica}

Las pruebas bioquímicas realizadas fueron catalasa, ketolactosa, producción de ácido o álcali, crecimiento en peptona glucosa agar (PGA) y en tres concentraciones de cloruro de sodio. Todos los ensayos fueron sembrados en cajas Petri por triplicado incluyendo controles negativos en cada prueba (Ferrera et al., 1993; Zúñiga, 2012).

\section{Resultados y Discusión 3.1 Caracterización fenotípica}

La coloración roja a rosada de los nódulos, coloración y velocidad de crecimiento de las colonias aisladas mostraron la presencia de bacterias bacilares Gram negativas y productoras de goma entre 1 a 4 días de crecimiento aisladas en el medio LMARC, son típicos de las rizobacterias (Figura 2) (Ferrera et al., 1993; Mantilla et al., 2009; Villanueva y Quintana, 2012).

Figura 2. (A) Corte transversal de un nódulo de $L$. leucocephala (Lam.) de coloración rojiza por la presencia de la leghemoglobina. (B) Aislados de nódulos en medio LMRC.
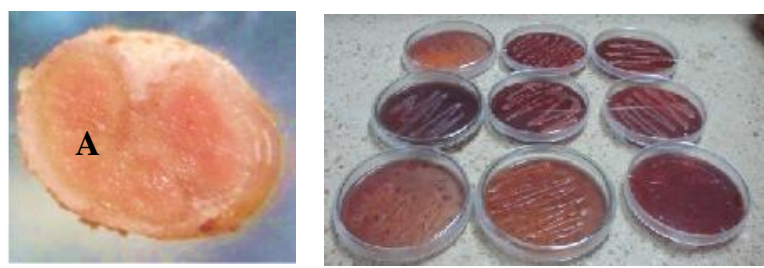

\subsection{Caracterización bioquímica}

Las pruebas bioquímicas de catalasa y crecimiento en PGA confirman características bacterianas metabólicas de los rizobios; la prueba de ketolactosa descarta la presencia del género Agrobacterium, contaminante común de los aislados (Toniutti, et al., 2015).

Las colonias de la cepa LEURV poseen morfología pulminada y es ácido productora, al cambiar el color del medio de púrpura al amarillo; mientras que LEUPSE 1 y LEUPSE 3 presentan formas convexas y no cambiaron el medio PGA, considerándose neutras o alcalino productoras. Los tres aislados presentaron color blanquecino rosáceo, producción de goma y sin crecimiento en el cloruro de sodio (Tabla 1 ).

Tabla 1. Origen y codificación de los aislados bacterianos.

\begin{tabular}{|c|c|c|c|c|c|c|c|c|}
\hline $\begin{array}{c}\text { Velocidad } \\
\text { Crecimimento } \\
\end{array}$ & Origen & Código & $\begin{array}{c}\text { Caracterización } \\
\text { morfológica }\end{array}$ & $\begin{array}{c}\text { Ácido } \\
\text { productora }\end{array}$ & Catalasa & Gram & $\begin{array}{l}\text { Crecimimito } \\
\text { PGA }\end{array}$ & $\begin{array}{c}\text { Crecimiento } \\
\text { NaCl }\end{array}$ \\
\hline 1-3 días & $\begin{array}{c}\text { Rio } \\
\text { verde }\end{array}$ & LEURV & $\mathrm{P}, \mathrm{BR}, \mathrm{G}$ & + & + & $(\cdot)$ & + & . \\
\hline 4 días & $\begin{array}{c}\text { La } \\
\text { Libertad }\end{array}$ & $\begin{array}{c}\text { LEUPSE } \\
1\end{array}$ & $\mathrm{C}, \mathrm{BR}, \mathrm{G}$ & . & + & $(\cdot)$ & + & . \\
\hline 4 días & $\begin{array}{c}\text { La } \\
\text { Libertad }\end{array}$ & $\begin{array}{c}\text { LEUPSE } \\
3\end{array}$ & $C, B R, G$ & . & + & $(\cdot)$ & + & . \\
\hline
\end{tabular}

Morfología de la colonia: $\mathrm{P}=$ Pulminada; $\mathrm{C}=$ Convexa Coloración de la colonia: $\mathrm{BR}=\mathrm{Blanquecina} \mathrm{rasada}$

Consistencia de la colonia: $\mathrm{G}=\mathrm{Gomosa}$

\subsection{SEM del interior de los nódulos y del aislado en cultivo en medio LMARC}

La microscopía de barrrido (SEM) de los nódulos de L. leucocephala (Lam.), confirma la presencia de bacterias bacilares, agrupadas y rodeadas por restos membranales y además con formas bacteroides "curvas" y en "Y" mecionados por Tu, 1974; Trinick, 1979; Chen y Rolfe, 1988 y Wang, et al. 2001.

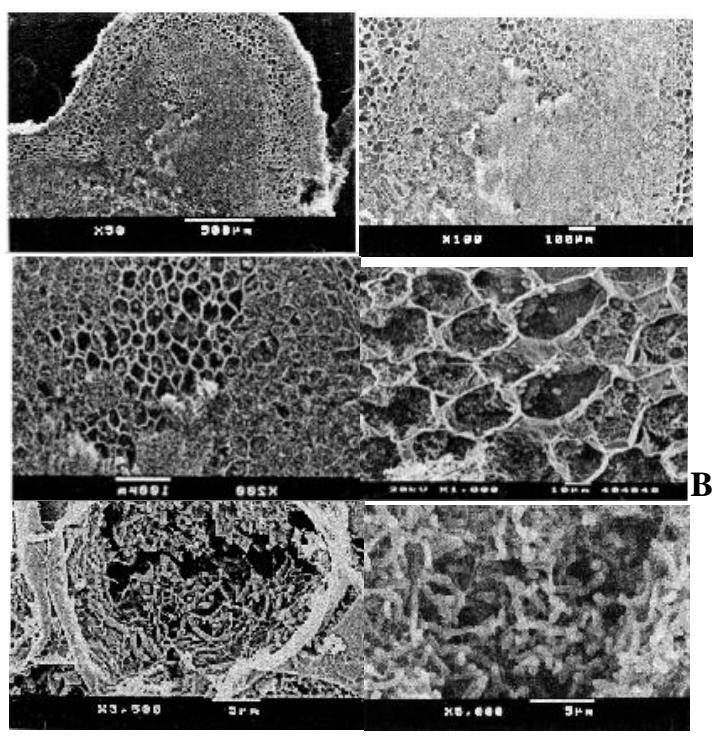

Figura 3. Secuencia de la magnificación a X50, X100, X200, X1 000, X3 500 y X5 000 de bacterias bacilares mezcladas 
con restos de membranas peribacteroidales al interior de un nódulo de L. leucocephala (Lam.).

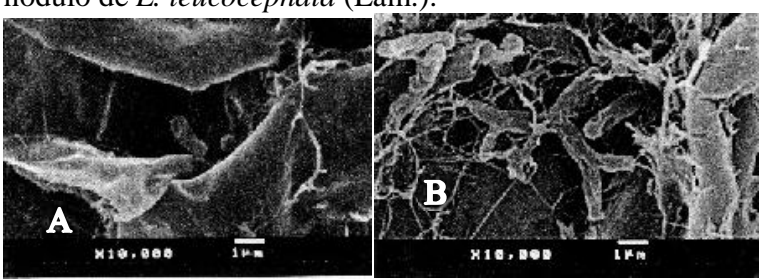

Figura 4. Microfotografía de dos secciones del interior nódular de L. leucocephala, a X10 000 de bacterias bacilares (A) y Bacteroides (B).

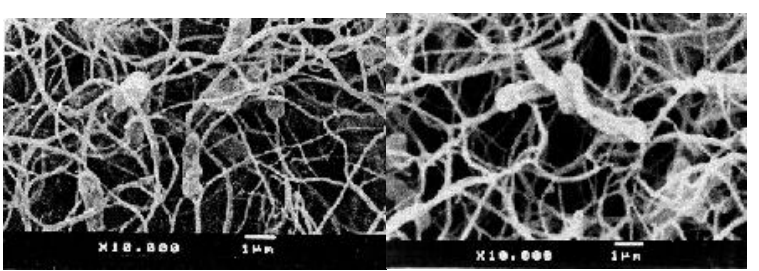

Figura 5. Comparación de dos secciones al interior del nódulo de L. leucocephala, a X10 000 de bacterias bacilares, en estado de infección avanzada.

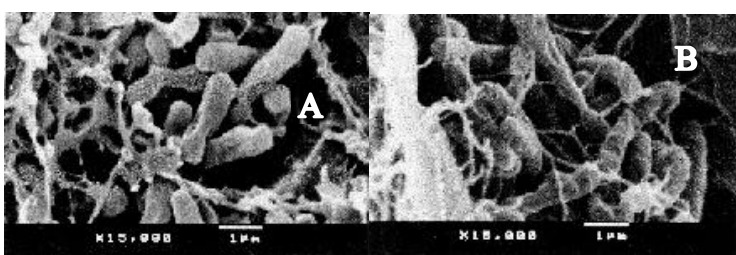

Figura 6. Dos secciones del interior nodular de $L$. leucocephala, a X15 000, mostrando formas bacteriodes (A) y Bacilos (B) con restos de membranas.

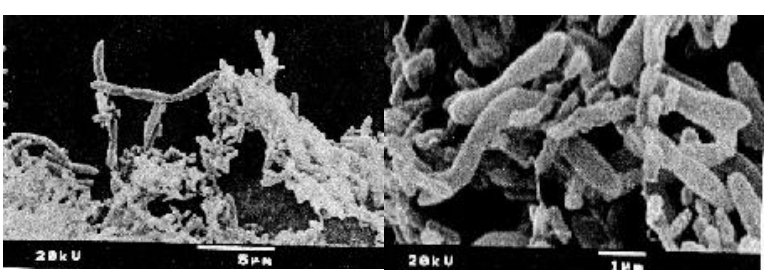

Figura 7. Microfotografías electrónicas del cultivo de los aislados de nódulos de L. leucocephala (Lam.), que muestra formas bacilares con magnificación $20 \mathrm{kv}$ a 5 y 1 .

\section{Conclusiones}

Se concluye que los microorganismos endófitos evidenciados al interior de los nódulos de Leucaena leucocephala (Lam) presentan características típicas relacionadas con los simbiontes de las leguminosas, similares a los reportados anteriormente por varios investigadores aquí reportados.

Finalmente, para complementar este estudio se recomienda emplear pruebas moleculares como la amplificación del gen16S RNAr y/o genes constitutivos que permitirían esclarecer la identificación y taxonomía adecuada de las rizobios encontrados. Así como el estudio de esta y otras leguminosas nativas que se podrían considerar para fines agroforestales por su importancia para la fijación de nitrógeno, aprovechamiento forrajero y uso maderable, adaptados a los ecosistemas locales.

\section{Agradecimientos}

Este trabajo forma parte del proyecto de investigación "Estudio del género Rhizobium para la producción de inoculante de uso agrícola en la Provincia de Santa Elena" del Centro de Investigaciones Agropecuarias (CIAP-UPSE). Agradecimiento especial al Biólogo Xavier Cornejo, MSc., curador del Herbario de la Universidad de Guayaquil.

\section{Referencias}

[1] Aguirre-Medina, J., De Cross, A., VelazcoZebadúa, M., Aguirre-Cadena, J. 2015. Crecimiento de Leucaena leucocephala (Lam.) De Wit inoculada con hongo micorrízico y bacteria fijadora de nitrógeno en vivero. Quehacer Científico en Chiapas 10 (1): 15-22.

[2] Centro Internacional de Agricultura Tropical (CIAT) 1987. Simbiosis leguminosa-Rizobio. Manual de evaluación, selección y manejo agronómico. 86p.

[3] Chen, H., Rolfe, B. 1988. Rhizobium Infection of Leucaena leucocephala via the Formation of Infection Threads in Curled Root Hairs. Journal Plant Physiology 332: 379-382.

[4] Comisión de estudios para el desarrollo de la cuenca del Río Guayas (CEDEGÉ) 1983. Plan Regional Integrado de la Cuenca del Río Guayas y de la Península de Santa Elena. Unidad de Planificación Regional. CEDEGÉ y CEPAL/ILPES. 61p.

[5] Elzanaty, A., Hewedy, O., Nagaty, H., AbdElbany, M. 2015. Molecular and Biochemical Characterization of Some Egyptian Genotypes Rhizobium (Vicia faba) Isolates. Journal Bioenginer \& Biomedicine Sci. 5: 1.

[6] Ferrera, R., González, M., Rodríguez, M. 1993. Manual de Agromicrobiología. Editorial Trillas. México. p. 142.

[7] Ferrera, R., Alarcón, A. 2001. La microbiología del suelo en la agricultura sostenible. Ciencia Ergo Sum.http://www.redalyc.org/articulo.oa?id=10402108 
[8] Hernández, J., Cubillos-Hinojosa, J., Milian, P. 2012. Aislamiento de cepas de Rhizobium spp., asociados a dos leguminosas forrajeras en el Centro Biotecnológico del Caribe. Revista Colombiana de Microbiología 2 (2): 51-62.

[9] Mantilla, A., Cardona, G., Peña, C., Murcia, U., Rodríguez, M., Zambrano, M. 2009. Distribución de bacterias potencialmente fijadoras de nitrógeno y su relación con parámetros fisicoquímicos en suelos con tres coberturas vegetales en el sur de la Amazonía colombiana. Revista Biología Tropical 57 (4): 915-927.

[10] Peix, A., Ramírez-Bahena, M., Velásquez, E., Bedmar, E. 2015. Bacterial Associations with Legumes. Critical Reviews in Plant Sciences 34 (1-3): $17-42$.

[11] Rangel, W., Thijs, S., Janssen, J., Oliveira, S., Bonaldi, D., Ribeiro, P., Jambon, I., Eevers, N., Weyens, N., Vangronsveld, J., Moreira, F. 2017. Native rhizobia from $\mathrm{Zn}$ mining soil promote the growth of Leucaena leucocephala on contaminated soil. International Journal of Phytoremediation 19 (2): 142-156.

[12] Schneider, J., Labory, C., Rangel, W., Guilerme, M. 2013. Anatomy and ultrastructure alterations of Leucaena leucocephala (Lam.) inoculated with mycorrhizal fungi in response to arsenic-contaminated soil. Journal of Hazardous Materials 262: 1245-1258.

[13] Soares, A., Araújo, S., Lopes, S., Costa, L. 2015. Anthelmintic activity of Leucaena leucocephala protein extracts on Haemonchus contortus. Revista Brasileira de Parasitologia Veterinária, 24(4): 396-401.

[14] Soto, J., Julio, A., Crespo, L., Borbor, G., Borbor, V. 2016. Efecto de la inoculación de bacterias nativas en dos híbridos de maíz (Zea mays L.), en la provincia de Santa Elena. Revista Científica y Tecnológica UPSE 3 (2): 50-60.
[15] Soto, J., Borbor, G., Borbor, V. 2012. Identificación y caracterización de cepas nativas de Rhizobium en la Provincia de Santa Elena. Revista Científica y Tecnológica UPSE 1 (1): 1-5.

[16] Trinick, M. 1979. Structure of nitrogen-fixing nodules formed by Rhizobium on roots of Parasponia andersonii Planch. Canadian Journal of Microbiology 25: $565-578$.

[17] Toniutti, M., Fornasero, L., Trod, B., Zuber, N., Córdoba, M. 2015. Caracterización fenotípica y funcional de rizobios noduladores de dos especies del género Macroptilium fave. Sección Ciencias Agrarias, 14 (1).

[18] Tu, J. 1974. Rhizobial root Nodules of Soybean as Revealed by Scanning and Transmission Electron Microscopy. Phytopathology 65: 447-454.

[19] Villanueva, E., Quintana, A. 2012. Aislamiento y selección de bacterias nativas de rizobios fijadores de nitrógeno, a partir de nódulos radiculares de Phaseolus vulgaris. Revista Científica Facultad de Ciencias Biológicas Universidad Nacional de Trujillo 32 (1):1-7.

[20] Wang, E., Martínez-Romero, J., López, I. 2001. Rhizobium y su destacada simbiosis con plantas. En: Microbios. Eds. E. Martínez Romero y J.C. Martínez Romero Centro de Investigaciones sobre Fijación de Nitrógeno. Universidad Nacional Autónoma de México, México DF.

[21]Xu, K., Penttinen, P., Chen, Y., Chen, Q., Zhang, X. 2012. Symbiotic efficiency and phylogeny of the rhizobia isolated from Leucaena leucocephala in aridhot river valley area in Panxi, Sichuan, China. Applied Microbiology and Biotechnology 97 (2): 783-793.

[22]Zúñiga, D. 2012. Manual de Microbiología Agrícola, Rhizobium, PGPRs, Indicadores de Fertilidad e Inocuidad. UNALM, Lima-Perú. 